\title{
GSTM1 and GSTT1 double null genotypes determining cell fate and proliferation as potential risk factors of relapse in children with hematological malignancies after hematopoietic stem cell transplantation
}

\author{
Simona Jurkovic Mlakar ${ }^{1,2}$. Satyanarayana Chakradhara Rao Uppugunduri ${ }^{1,2} \cdot \operatorname{Tiago~Nava}^{1,2} \cdot \operatorname{Vid}_{\text {Mlakar }}{ }^{1,2}$. \\ Hadrien Golay ${ }^{1,2}$. Shannon Robin ${ }^{1,2} \cdot$ Nicolas Waespe $^{1,3} \cdot$ Mohamed Aziz Rezgui $^{4} \cdot$ Yves Chalandon $^{5}$. \\ Jaap Jan Boelens ${ }^{6} \cdot$ Robert G. M. Bredius $^{7}$. Jean-Hugues Dalle ${ }^{8} \cdot$ Christina Peters $^{9} \cdot$ Selim Corbacioglu $^{10}$. $^{4}$ \\ Henrique Bittencourt ${ }^{4,11,12,13}$ - Maja Krajinovic ${ }^{4,11,12,13} \cdot$ Marc Ansari $^{1,2}$ (D) on behalf of the paediatric diseases \\ working party of the European society for blood and marrow transplantation
}

Received: 6 July 2021 / Accepted: 14 August 2021 / Published online: 9 September 2021

(C) The Author(s) 2021, corrected publication 2021

\begin{abstract}
Purpose This study aimed to retrospectively evaluate the genetic association of null variants of glutathione S-transferases GSTM1 and GSTT1 with relapse incidence in children with hematological malignancies (HMs) undergoing busulfan (BU)containing allogeneic hematopoietic stem cell transplantation (HSCT) and to assess the impact of these variants on BUinduced cytotoxicity on the immortalized lymphoblastoid cell lines (LCLs) and tumor THP1 GST gene-edited cell models. Methods GSTM1- and GSTT1-null alleles were genotyped using germline DNA from whole blood prior to a conditioning BU-based regimen. Association of GSTM1- and GSTT1-null variants with relapse incidence was analyzed using multivariable competing risk analysis. BU-induced cell death studies were conducted in GSTs- null and non-null LCLs and CRISPR-Cas9 gene-edited THP1 leukemia cell lines.

Results Carrying GSTM1/GSTT1 double null genotype was found to be an independent risk factor for post-HSCT relapse in 86 children (adjusted HR: 6.52 [95\% Cl, 2.76-15.42; $\left.p=1.9 \times 10^{-5}\right]$ ). BU-induced cell death preferentially in THP1 ${ }^{\text {GSTM1(non-null) }}$ and LCLs ${ }^{G S T M 1(n o n-n u l l)}$ as shown by decreased viability, increased necrosis and levels of the oxidized form of glutathione compared to null cells, while GSTT1 non-null cells showed increased baseline proliferation.

Conclusion The clinical association suggests that GSTM1/GSTT1 double null genotype could serve as genetic stratification biomarker for the high risk of post-HSCT relapse. Functional studies have indicated that GSTM1 status modulates BUinduced cell death. On the other hand, GSTT1 is proposed to be involved in baseline cell proliferation.
\end{abstract}

Keywords Null genotypes of glutathione S-transferases $\cdot$ Acute leukemia $\cdot$ Hematological malignancies $\cdot$ Hematopoietic stem cell transplantation $\cdot$ Post-transplant relapse $\cdot$ Busulfan resistance

\section{Background}

Survival rates of children with hematological malignancies (HMs) undergoing allogeneic hematopoietic stem cell transplantation (HSCT) have improved over the years achieving

Marc Ansari

marc.ansari@hcuge.ch

Extended author information available on the last page of the article
91\% estimated 2-year overall survival. The improvement is mainly attributed to reduced HSCT-related toxicity and mortality. The incidence of post-HSCT relapse remains a significant complication and varies from 12 to $33 \%$ after 2 years (Peters et al. 2021). Risk factors that influence transplant success are on the one hand host- and disease related, such as disease genetics and remission status before HSCT, and on the other hand, transplant related, such as conditioning regimen and treatment-related toxicities including for example severe graft-versus-host disease (GvHD), sinusoidal obstruction syndrome (SOS), and infections (Barrett and 
Battiwalla 2010; Hamilton and Copelan 2012; Shah et al. 2014).

A bifunctional alkylating agent busulfan (BU) is still often used in conditioning regimens prior to HSCT in children and adolescents (Philippe et al. 2016) and is commonly administered along with other chemotherapeutics, e.g., cyclophosphamide (CY) and fludarabine (FLU) (Ciurea and Andersson 2009; Hao et al. 2020). At least in acute myeloid leukemia (AML), BU has shown lower long-term adverse effects, consequently replacing total body irradiation (TBI) in the conditioning regimen (Lee et al. 2020). In acute lymphoblastic leukemia (ALL), although the recently published results showed lower rates of relapse after TBIcontaining conditioning, the results obtained with $\mathrm{BU}$ in association with FLU and thiotepa were encouraging and indicate an opportunity to find genetic subgroups of patients who might benefit from the TBI-free conditioning (Peters et al. 2021).

BU is metabolized via conjugation with glutathione (GSH) in the liver, which is predominantly catalyzed by glutathione S-transferase alpha1 (GSTA1) (Czerwinski et al. 1996). In hematopoietic cells (HCs), where GSTA1 is not expressed (Czerwinski et al. 1997), other GST isoenzymes, particularly Mu1 (GSTM1, 46\% of the BU conjugating activity of GSTA1 (Czerwinski et al. 1996)) might play the most important role. The role of GSTT1 in BU conjugation is not yet known, but has been mostly reported to have combined effects with GSTM1 on clinical outcomes (Kim et al. 2011; Myers et al. 2017). In addition to their protective role of the conjugation of $\mathrm{BU}$ in $\mathrm{HCs}$, they might contribute to multiple cellular processes such as regulation of cell proliferation and apoptosis through the interaction with protein kinases such as apoptosis signal-regulating kinase 1 (ASK1). Under stress conditions, the interaction of the GSTM1:ASK1 complex is dissociated and results in activation of ASK1 that activates the c-Jun N-terminal kinase (JNK) and mitogen-activated protein kinase p38 (MAPK p38) pathways, leading to upstream cytokine- and stress-induced apoptosis (Board and Menon 2013; Tew and Townsend 2012). However, the impact of apoptosis through kinases on BU-dependent cytotoxicity is poorly understood and even less whether those GST genes naturally knocked down might interfere in the post-HSCT relapse potential.

GSTM1 and GSTT1 genes can be homozygously deleted (presented as GSTM1-null and GSTT1-null) and thus completely deprived of the enzyme activities in a high percentage of individuals (the average \% in Europe are 51 and 19, respectively) (Saitou and Ishida 2015). In AML adult patients, Weiss et al. (Weiss et al. 2007) showed a perfect concordance of those variants in malignant and germline DNA, which suggests that the germline genotype drives protein expression in malignant cells. Although these variants have been associated with a higher risk of leukemia development ( $\mathrm{Li}$ et al. 2018), there are conflicting reports on the association of the GSTM1-null and GSTT1-null variants with relapse in patients with HMs (Balta et al. 2003; Franca et al. 2012; Stanulla et al. 2000; Takanashi et al. 2003). To date, there is no evidence available for the association of germline GSTM1-null and GSTT1-null variants with postHSCT relapse in children with HMs.

Because GSTM1 and GSTT1 are the main remaining GSTs in HCs, we hypothesized that the absence of either or both proteins should affect BU cytotoxicity through conjugation-dependent or -independent ways, interfering in the HSCT outcomes. Hence, a genetic association study based on germline GSTT1 - and GSTM1-null variants was undertaken. Further, we conducted in vitro functional analyses to understand the role of these variants in survival and BU-induced apoptosis and necrosis of the immortalized and tumor lymphoblastoid cell lines (LCLs).

\section{Materials and methods}

\section{Clinical association study}

\section{Patients and treatment}

Pediatric patients with ALL, AML or myelodysplastic syndrome (MDS) who had undergone allogeneic HSCT between 2000 and 2013 were enrolled in the study. The Institutional Review Board or ethics committees approved the study and all patients and/or parents provided informed consent. The present study is a subset of the multicentric study under the umbrella of the European Society for Blood and Marrow Transplantation (EBMT) (Clinicaltrials.gov identifier: NCT01257854) (Ansari et al. 2017).

I.v. BU (Busulfex, Otsuka Pharmaceuticals, Saint-Laurent, Montreal, QC, Canada or Busilvex, Pierre Fabre Laboratory, Paris, France) administration was given as a $2 \mathrm{~h}$ infusion to the patients, every $6 \mathrm{~h}$ for a total of 16 doses. The first BU dose was age and weight based and pharmacokinetic (PK)-guided dose adjustment was performed to obtain a cumulative area under the curve (CumAUC) between 59.2 and $98.56 \mathrm{mg} * \mathrm{~h} / \mathrm{L}$ as reported previously (Ansari et al. 2017).

The primary diagnosis of HMs was made at the referring institution. Patients were considered to be in remission after chemotherapy if they presented $<5 \%$ blasts in the normal cellular bone marrow. Relapse in MDS was defined as $>5 \%$ and $\leq 20 \%$ of blasts at the bone marrow examination after engraftment and/or reappearance of major dysplastic features associated with cytopenias and/ or mixed chimerism $>5 \%$ and/or detection of the same cytogenetic abnormality present at diagnosis. Relapse in AML and ALL was defined as the presence of blasts in the 
bone marrow $>5 \%$, confirmed by flow cytometry; detection of the gene fusion present at diagnosis; or according to minimal residual disease (MRD) results after the transplantation if available. Disease remission status was defined by the number of bone marrow remission or relapse events before HSCT.

Cumulative relapse incidence, event-free survival (EFS), and overall survival (OS) were defined according to the standard guidelines of EBMT and as detailed in our recent report (Ansari et al. 2017). EFS was calculated from the time of transplant until death, relapse, or graft failure, whichever occurred first. OS was calculated from the time of transplant until death from any cause.

\section{Genotyping and statistical analysis}

Genotyping of GSTM1-null and GSTT1-null variants was performed on germline DNA, extracted from whole blood or peripheral mononuclear cells of all patients before the first HSCT as described by Lin et al. (1998).

Pearson Chi-square test was used to analyze the differences in demographics between groups with and without GST-null variants. Estimated cumulative relapse incidence by competing risk analysis with non-relapse mortality as a competing event and the difference among groups were estimated by Gray's test (Gray 1988). The Fine-Gray model was used for competing risk regression in multivariable analysis to obtain adjusted $p$ values for all the variables in relation to the genotype groups (Fine and Gray 1999). The potential risk factors with a $p$ value $\leq 0.25$ in the univariable competing risk analysis were retained in the multivariable analysis by including the GST genotype factor with the lowest $p$ value. The final multivariable analysis included: diagnosis (ALL, AML and MDS), disease status [1st complete remission (CR), a higher degree of CRs and absence of CR], conditioning regimen (standard regimen with two alkylating agents and intensified regimen with three alkylating agents), AUC after the first dose of busulfan (1st BU dose AUC categorized into below 3.7, between 3.7 and 6.16 , and above $6.16 \mathrm{mg} * \mathrm{~h} / \mathrm{L}$ ) and BU CumAUC (below 59.2, between 59.2 and 98.6, and above $98.6 \mathrm{mg} * \mathrm{~h} / \mathrm{L}$ ) as categorical variables. Cumulative incidences of OS and EFS were estimated in relation to the genotype groups, using Kaplan-Meier framework and log-rank test. Univariate Cox regression was used to estimate hazard ratios.

All statistical analyses on clinical data were performed using SPSS (RRID: SCR_002865, Version 24.0. Armonk, NY: IBM Corp.) and R Project for Statistical Computing (version 3.6.2, RRID: SCR_001905) with Rcmdr package (version 2.6.1). Statistical power calculations according to GST variants were conducted in G*Power-Statistical Power
Analyses for Windows and Mac, version 3.1.9.2 (RRID: SCR_013726; Dusseldorf, Germany).

\section{In vitro functional studies of the associated variants}

\section{Cell models design and cell characterization}

A set of 56 immortalized non-malignant lymphoblastoid cell lines (LCLs), acquired in 2012 from International HapMap Consortium's CEPH Families Reference Panel 142,011/147712 (Coriell Cell Repository, Camden, NJ, USA), and a human monocytic leukemia cell line (THP1; acquired in 2018 from ATCC, Cat\# TIB-202, RRID: CVCL_0006; Manassas, Virginia, USA), derived from a 1-year-old patient, were used for baseline and BU-induced functional assessment of GSTM1-null and GSTT1-null variants. The cells were immediately stored at $-196^{\circ} \mathrm{C}$ and were not used prior to the start of experiments. The cell lines were thawed and cultured in Roswell Park Memorial Institute Medium (RPMI) 1640 medium (Gibco, Carlsbad, CA) supplemented with $10 \%$ fetal bovine serum (HyClone, South Logan, UT) and $1 \%$ penicillin-streptomycin (Gibco) and incubated at $37{ }^{\circ} \mathrm{C}, 5 \% \mathrm{CO}_{2}$-humidified atmosphere according to the manufacturer's recommendations. The number of passages between thawing and use in each in vitro experiment achieved the range between 5 and 15 times. The IDs of investigated LCLs used for each particular in vitro experiment are listed in Supplementary Table 1.

THP1 GSTM1- and GSTT1-knockout cell lines (THP $1^{\text {GSTM1(-)- }}$ and THP $1^{\text {GSTT1(-/-) }}$ ) were prepared from parental THP1 representing non-null genotype for GSTM1 (THP1 $1^{\text {GSTM1(+/+) }}$ ) and GSTT1 (THP1 $1^{\text {GSTT1(+/+) }}$ using CRISPR/Cas9 gene-editing method. Plasmid PX458 containing 5'-TGATACTGGGGTACTGGGAC-3' gRNA (GSTM1) or 5'-TGAAGGACGGGGACTTCACC-3' gRNA (GSTT1) (prepared by GeneScript, The Netherlands) was transfected into THP1 cells. 10,000 cells were fluorescenceactivated cell sorted (FACS) in 24-well plates based on the presence of green fluorescence protein (GFP) $48 \mathrm{~h}$ posttransfection. After 48-72 h of recovery, THP1 cells were single-cell cloned in 96-well plates using FACS. Gene-modified clones were genotyped for the presence of deleterious mutations using Sanger sequencing and confirmed by Western blot for the success of gene knockout. Five clones of the same genotype were pooled in a population.

DNA and proteins of the selected cell lines (LCLs, THP $1^{\text {GSTM1(-/-) }}$ and THP $1^{\text {GSTT1(-/-) }}$ cell models) were extracted using DNeasy Blood and Tissue Kit (Qiagen, Hilden, Germany) and standard protein extraction protocol for western blot using RIPA lysis buffer (Sigma-Aldrich, Germany), respectively. The intracellular concentration of extracted proteins was measured using Bradford assay from Bio-Rad (Hercules, CA) according to the manufacturer's 
recommendations. Aliquots containing $20 \mu \mathrm{g}$ of proteins, sample reducing agent and LDS sample buffer (Thermo Fisher Scientific, USA) were subjected to electrophoresis by using Invitrogen Novex Tris-Glycine Gels (Thermo Fisher Scientific, USA). Dry transfer to a nitrocellulose membrane was performed with the iBlot dry blotting system (ThermoFisher Scientific, USA). A membrane was blocked using 5\% milk in PBS and $0.05 \%$ Tween 20 . The following primary antibodies were used for protein labeling: B-Actin Mouse monoclonal antibody (Abcam Cat\# ab6276, RRID: AB_2223210); GSTP1 Monoclonal Antibody Rabbit (DSHB Cat\# CPTC-GSTP1-1, RRID: AB_2617266); GSTM1 Monoclonal Antibody Mouse (Thermo FisherScientific Cat\# MA5-17,085, RRID: AB_2538556) and GSTT1 Polyclonal antibody Rabbit (Thermo FisherScientific Cat\# PA5-22,011, RRID: AB_11154445). Lumi-Light WB Substrate (Roche, $\mathrm{CH}$ ) was used for the detection of the secondary antibody linked with horseradish peroxidase (HRP). Band intensities were identified using Syngene G-Box System (Syngene, Frederick, MD, USA).

The glutathione transferase activity (Glutathione S-transferase [GST] Assay Kit, Sigma-Aldrich, USA) was measured on cell lysates obtained from one million cells (THP $1^{\text {GSTM1(-/-) }}$ and THP $1^{\text {GSTM1(+/+)}}$ ) by measuring absorbance at $340 \mathrm{~nm}$ every minute for $10 \mathrm{~min}$ in a $200 \mu \mathrm{l}$ well of a 96-well plate using Spectramax ID3 Multi-Mode microplate reader (Molecular Devices, USA) according to the manufacturer's recommendations. GST activity was calculated as the following: $[\Delta 340 \mathrm{~nm}(\mathrm{~min}) *$ total volume of the reaction $(\mathrm{ml})] /\left[5.3 \mathrm{mM}^{-1} *\right.$ volume of enzyme] corrected according to the protein concentration in $\mathrm{mg} / \mathrm{ml}$ obtained by using a Pierce $^{\mathrm{TM}}$ BCA Protein Assay Kit (ThermoFisher Scientific, USA) according to the manufacturer's guidelines.

The results of the characterization of CRISPR-Cas9 THP1 gene-edited cell models with target proteins (GSTM1, GSTT1 and GSTP1) and GST activity are presented in Supplementary Fig. 1 (A-C).

DNA samples from LCLs were genotyped for GSTM1null and GSTT1-null variants using multiplex real-time PCR amplification in the presence of SYBR Green I and genotype discrimination by melting curve analysis in a StepOnePlus ${ }^{\mathrm{TM}}$ Real-Time PCR System (Applied Biosystems ${ }^{\mathrm{TM}}$, Foster City, CA, USA) with BCL2 (BCL2 apoptosis regulator) gene as an internal control as described earlier (Marin et al. 2010). The genotyping method used cannot differentiate the heterozygous individuals from homozygous non-null carriers (furtherly marked as $\operatorname{GSTM1}(+)$ and $\operatorname{GSTT1}(+)$ ) except when using Sanger sequencing.
Cell viability, apoptosis, necrosis, GSSG/GSH measurements, and caspase activities

Intracellular ATP concentrations (CellTiter 2.0 Luminescent Cell Viability Assay (Promega Corporation, Madison, WI)) were screened in 56 LCLs and CRISPR-Cas9 gene-edited cell models: THP $1^{\text {GSTM1(-/-) }}$, THP $1^{\text {GSTM1(+/+), }}$

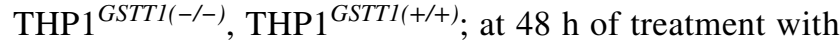
$100,200,400,800$ and $1600 \mu \mathrm{M}$ concentrations of BU (Sigma-Aldrich, Germany) reconstituted with DMSO (Sigma), $1 \%$ of DMSO (as control) and at baseline (medium only). For validation of the first screening, ATP-independent cell viability follow-up $(72 \mathrm{~h})$ was performed at BU concentrations of 100,250 and $500 \mu \mathrm{M}$ in three GSTM1(+) and four GSTM1(-/-) LCLs (Supplementary Table 1) and at baseline in THP $1^{G S T T 1(-/)}$ and THP $1^{\text {GSTT1(+/+) }}$ using RealTimeGlo $^{\mathrm{MT}}$ Cell Viability Assay (Promega, USA).

Annexin V/PI assay (BD Biosciences) was used to measure live, early and late apoptotic and necrotic cells. Prior to FACS, ten GSTMI(+) and ten GSTMI(-/-) LCLs (Supplementary Table 1) were treated for $48 \mathrm{~h}$ with BU (1\% DMSO) at 250, 500 and $1000 \mu \mathrm{M}$ and two samples of each cell line were used as controls (1\% DMSO and untreated). One million cells were labeled according to the manufacturer's protocol. FACS analysis was performed using the CyAN ADP system (Beckman Coulter, UK). Results were analyzed by Kaluza analysis software, version 1.3 (Beckman Coulter, UK). Apoptosis and necrosis were followed for $72 \mathrm{~h}$ in six GSTM1(+) and six GSTM1(-/-) LCLs (Supplementary Table 1) treated with $500 \mu \mathrm{M}$ BU using RealTime-Glo ${ }^{\mathrm{MT}}$ Annexin $\mathrm{V}$ Apoptosis and Necrosis Assay (Promega).

Concentrations of the total $\left(\mathrm{GSH}_{\mathrm{T}}\right)$ (GSH-Glo Glutathione Assays, Promega, USA) and oxidized intracellular glutathione (GSSG) (GSH/GSSG-Glo Glutathione Assays, Promega, USA) were measured according to the manufacturers' recommendations. Prior to measurement, cells from five GSTM1(+) and five GSTM1(-/-) LCLs and CRISPR-Cas9 gene-edited THP1 cell models were incubated for $48 \mathrm{~h}$ at $500 \mu \mathrm{M} \mathrm{BU}$ and 1\% DMSO (control). Results are expressed as the relative proportion of GSSG to $\mathrm{GSH}_{\mathrm{T}}$.

Caspase-Glo 3/7 assay (Promega) was used to measure the total activity of caspases-3 and -7 in a subset of 12 LCLs (Supplementary Table 1) and CRISPR-Cas9 gene-edited THP1 cell models at $48 \mathrm{~h}$ BU post-treatment (250, 500 and $1000 \mu \mathrm{M})$.

Chemiluminescent signals were measured using Victor3 (Perkin Elmer, Inc., USA). All BU-based data were normalized relative to the negative controls with $1 \%$ DMSO.

\section{Statistical analyses in in vitro functional studies}

The cell-based experiments $\left(\mathrm{IC}_{50}\right.$ distribution, end-point apoptosis and necrosis, real-time monitoring of viability, 
apoptosis and necrosis, Caspase 3/7 activities; and [GSSG/ $\left.\mathrm{GSH}_{\mathrm{T}}\right]$ ratios) were performed at least in duplicate and results are reported as observed means \pm SD stratified by GST-null and GST-non-null variants. Statistical differences between genotypes were assessed using Mann-Whitney, $t$ tests, or two-way ANOVA according to the normality of the distribution and compared to untreated controls using GraphPad Prism 7 software (RRID: SCR_002798). We considered $p<0.05$ to be statistically significant in all analyses.

\section{Results}

\section{GSTM1- and GSTT1-double null genotypes are associated with higher relapse incidence}

Eighty-six children with malignancies aged 5 months-18 years (female/male, 44/42), who received myeloablative conditioning containing four-times-daily i.v. BU followed by HSCT, were enrolled in this study. The patients' baseline characteristics at the time of their HSCT are summarized in Table 1. The number of patients who had experienced relapse was 16 (18.6\% of included patients) with the median time to onset 203 days (range 35 to 817 ) and 12 (14.0\%) patients died with the median time to onset 221 days (range 15 to 979). The median CumAUC of BU achieved $56.96 \mathrm{mg} * \mathrm{~h} / \mathrm{L}$ (concentration range $30.50-115.23 \mathrm{mg} * \mathrm{~h} / \mathrm{L}$ ).

Regarding the genotype frequency, 49 patients were GSTM1-null (57.0\%), 24 GSTT1-null (27.9\%) and 9 had null genotypes in both GSTM1 and GSTTI genes (10.5\%). Characteristics of these patients according to GSTM1-null and GSTT1-null variants are shown in Supplementary Table 2.

Relapse was associated with GSTT1-null compared to GSTT1-non-null subgroups ( $42.1 \%$ vs $16.1 \%)$ in the univariable analysis ( $p=0.04$, Fig. 1A, Table 2A). The GSTM1-null was not associated with relapse (Fig. 1B, Table 2A). However, patients carrying null genotypes in both GSTMI and GSTT1 genes showed significantly increased risk of relapse compared to other genotype subgroups ([GSTM1-non-null/ GSTT1-non-null, GSTM1-non-null/GSTT1-null and GSTM1null/GSTT1-non-null]; $p=0.012$, Fig. 1C, Table 2A) and this risk remained significant when other genotype subgroups were grouped together (using a gene-gene interaction model; $77.8 \%$ vs. $19.0 \%$; $p=0.002$, Fig. 1 D, Table $2 B$ ). Significantly lower EFS was observed in the group of patients carrying (-/-) alleles in both GSTM1 and GSTT1 genes in comparison to others $(54.2 \%$ vs. $11.1 \%, p<0.001$, Supplementary Fig. 2A). When gene variants were analyzed independently, none of them affected the EFS (data not presented). OS was not significantly associated with GSTnull variants (using gene-gene interaction model; $67,1 \%$ vs. $37,0 \%, p=0.401$, Supplementary Fig. 2B).
Table 1 Demographic and transplantation characteristics of pediatric patients at the time of HSCT and events follow-up

\begin{tabular}{|c|c|}
\hline Variables & $N(\%)$ \\
\hline \multicolumn{2}{|l|}{ Sex } \\
\hline Male & $42(48,8)$ \\
\hline Female & $44(51,2)$ \\
\hline \multicolumn{2}{|l|}{ Ethnicity } \\
\hline Caucasian & $68(79,1)$ \\
\hline Other & $18(20,9)$ \\
\hline \multicolumn{2}{|l|}{ Diagnosis } \\
\hline ALL & $12(14,0)$ \\
\hline AML & $43(50,0)$ \\
\hline MDS & $31(36,0)$ \\
\hline \multicolumn{2}{|l|}{ Stem cell source } \\
\hline $\mathrm{BM}$ & $35(40,7)$ \\
\hline CB & $47(54,7)$ \\
\hline PBSCs & $4(4,7)$ \\
\hline \multicolumn{2}{|l|}{ Regimen conditioning } \\
\hline Busulfan/cyclophosphamide & $64(74,4)$ \\
\hline Busulfan/melphalane & $2(2,3)$ \\
\hline Busulfan/cyclophosphamide/melphalane & $13(15,1)$ \\
\hline Busulfan/cyclophosphamide/etoposide & $7(8,1)$ \\
\hline \multicolumn{2}{|l|}{ Serotherapy } \\
\hline No & $31(36,0)$ \\
\hline ATG & $55(64,0)$ \\
\hline \multicolumn{2}{|l|}{ HLA match compatibility } \\
\hline MRD & $28(32,6)$ \\
\hline MUD & $19(22,1)$ \\
\hline MMRD & $3(3,5)$ \\
\hline MMUD & $36(41,9)$ \\
\hline \multicolumn{2}{|l|}{ Disease phase } \\
\hline CR1 & $38(44,2)$ \\
\hline CR2 & $10(11,6)$ \\
\hline CR3 or more* & $9(10,5)$ \\
\hline Never treated & $24(27,5)$ \\
\hline ND & $5(5,8)$ \\
\hline \multicolumn{2}{|l|}{ Intensity of conditioning ${ }^{\#}$} \\
\hline 2 & $66(76,7)$ \\
\hline \multirow[t]{2}{*}{3 or more } & $20(23,3)$ \\
\hline & Median (range) \\
\hline Age at HSCT (years) & $6,5(0,5-18,2)$ \\
\hline Weight (kg) & $24,5(6,0-87,9)$ \\
\hline Height $(\mathrm{cm})$ & $122,5(51,0-183,0)$ \\
\hline
\end{tabular}

$A L L$ acute lymphoblastic leukemia; $A M L$ acute myeloid leukemia; $B M$, bone marrow; $B U$, busulfan; $C B$ cord blood; $C R l$ first complete remission; $C R 2$ second complete remission; $C R 3$ third complete remission; HLA identical sibling; $M D S$ myelodysplastic syndrome; $M M U D$ non-identical unrelated; $M M R D$ non-identical related; $M U D$ identical unrelated; $M R D$ identical related; $N D$ no data; $P B S C s$ peripheral blood stem cells

*Disease phase "CR3 or more" included all patients either in CR3 or more or in partial remission or those with $>10 \%$ of circulating myeloblasts before conditioning

\#2 alkylating agents (busulfan with cyclophosphamide or melphalan) and 3 agents (busulfan/cyclophosphamide with melphalan or etoposide) The enrolled patients were from CHU St Justine (Montreal, Quebec, 
Table 1 (continued)

Canada), The Hospital for Sick Children (Toronto, Ontario, Canada), Robert Debre University Hospital (Paris, France), Leiden University Medical Center (Leiden, Netherlands) and Geneva University Hospital (Geneva, Switzerland)

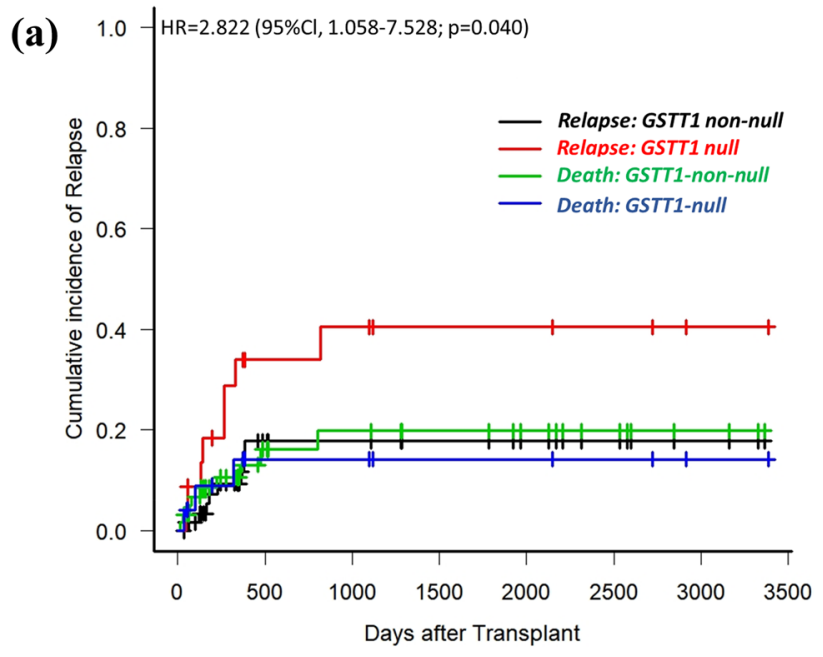

\begin{tabular}{l|cccccccc} 
GSTT1 non-null & 62 & 20 & 17 & 14 & 11 & 7 & 3 & 0 \\
GSTT1 null & 24 & 8 & 7 & 4 & 4 & 3 & 1 & 0 \\
\cline { 2 - 6 } & \multicolumn{7}{c}{ Number at risk }
\end{tabular}

(c)

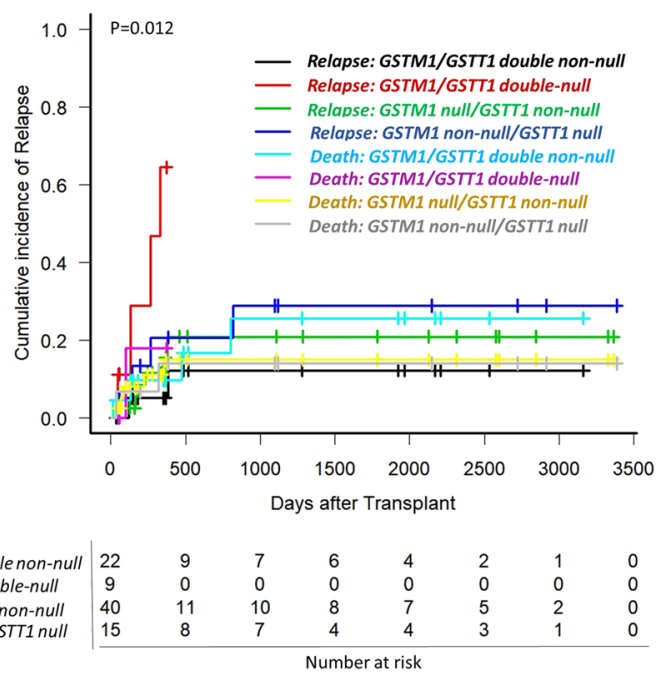

Fig. 1 Cumulative incidence plots of relapse in univariable competing risk analyses stratified by GST-null variants. Results are plotted for (A) GSTT1(-/-) group versus groups GSTT1( \pm ) and GSTT1(+/+) together presented as GSTT1(+); (B) GSTM1(-/-) group versus groups $\operatorname{GSTM1}( \pm)$ and $\operatorname{GSTM1}(+/+)$ together presented as $\operatorname{GSTM1}(+) ;(\mathbf{C})$ combined $\operatorname{GSTM1}(-/-) / \operatorname{GSTT1}(-/-)$ versus other genotype combinations $[\operatorname{GSTM} 1(-/-) / \operatorname{GSTT} 1(+)$, $\operatorname{GSTM1}(+) / \operatorname{GSTT1}(-/-)$ and $\operatorname{GSTM1}(+) / G S T T 1(+)] ;(\mathbf{D})$ combined
Relapse was compared between GSTM1-null and GSTT1-null variants combined with other possible risk factors (Table 2B). GSTM1/GSTT1 double null status was independently associated with relapse with an HR of $6.52\left[95 \% \mathrm{Cl}, 2.76-15.42 ; p=1.9 \times 10^{-5}\right] .25 \%, 9.7 \%$ and $23.3 \%$ of patients with ALL, MDS and AML, respectively, were relapsed. Among them, all relapsed patients with the GSTT1-null genotype had ALL (Supplementary Table 3).

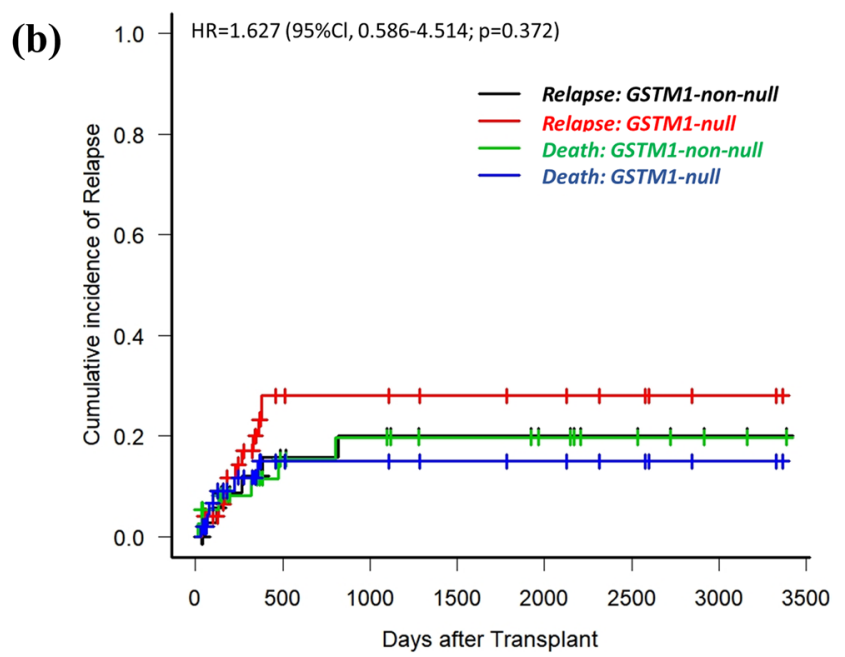

\begin{tabular}{l|rrrrrrrr} 
GSTM1 non-null & 37 & 17 & 14 & 10 & 8 & 5 & 2 & 0 \\
GSTM1 null & 49 & 11 & 10 & 8 & 7 & 5 & 2 & 0 \\
\cline { 2 - 7 } & \multicolumn{7}{c}{ Number at risk }
\end{tabular}

(d)

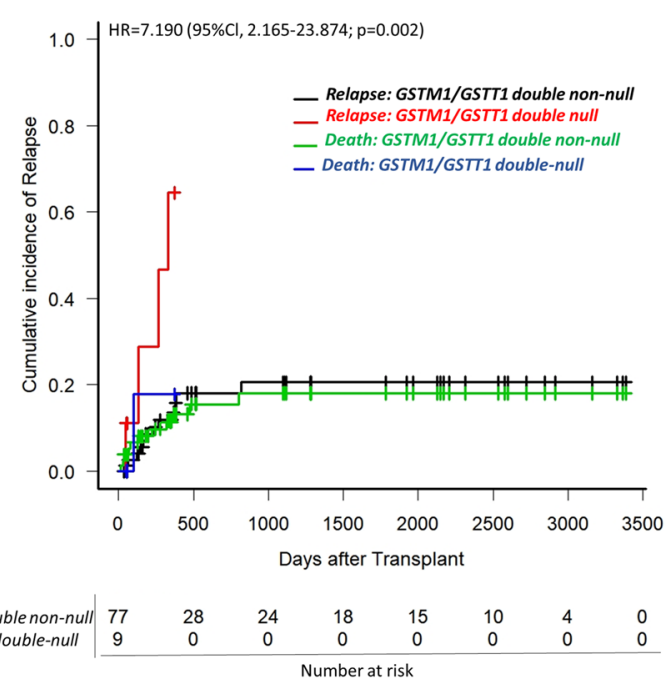

GSTM1(-/-)/GSTT1(-/-) versus grouped other genotype combinations $[G S T M 1(+) / G S T T 1(+)] . p$ values for the difference in cumulative incidence of relapse were calculated with Gray's test with death as a competing event. HR, hazard ratio; GSTM1-null and GSTT1-null are presented as GSTM1(-/-) and GSTT1(-/-), respectively. GSTM1 non-null and GSTT1 non-null genotypes are presented as GSTM1(+) and $G S T T 1(+)$, respectively 
Table 2 Relationship between GSTM1-null and GSTT1-null variants and other risk factors with a cumulative incidence of relapse in univariable and multivariable competing risk analyses (Fine-Gray's test)

\begin{tabular}{|c|c|c|c|}
\hline \multirow[t]{2}{*}{ Covariable } & \multicolumn{3}{|c|}{ Univariable analysis } \\
\hline & HR & $95 \% \mathrm{Cl}$ & $p$ value (C Risk) \\
\hline \multicolumn{4}{|l|}{ GSTM1 genotype } \\
\hline & & & 0.372 \\
\hline $\operatorname{GSTM1}(+)^{(N=37)}$ & Reference & 1 & \\
\hline $\operatorname{GSTM1}(-/-)^{(N=49)}$ & 1.627 & $(0.586-4.514)$ & \\
\hline \multicolumn{4}{|l|}{ GSTT1 genotype } \\
\hline & & & 0.040 \\
\hline $\operatorname{GSTT1}(+)^{(N=62)}$ & Reference & 1 & \\
\hline $\operatorname{GSTT1}(-/-)^{(N=24)}$ & 2.822 & $(1.058-7.528)$ & \\
\hline \multicolumn{4}{|c|}{ GSTM1 and GSTT1 genotypes (4 groups) } \\
\hline & & & 0.012 \\
\hline $\operatorname{GSTM1}(+)$ and $\operatorname{GSTT1}(+)^{(N=22)}$ & Reference & 1 & \\
\hline GSTM1(-/-) and GSTT1 (-/- $)^{(N=9)}$ & 12.836 & $(2.218-74.274)$ & \\
\hline $\operatorname{GSTM1}(-/-)$ and $\operatorname{GSTT1}(+)^{(N=40)}$ & 1.879 & $(0.378-9.354)$ & \\
\hline GSTM1(+) and GSTT1(-/-) $)^{(N=15)}$ & 2.614 & $(0.478-14.300)$ & \\
\hline
\end{tabular}
B)

\begin{tabular}{|c|c|c|c|c|c|c|}
\hline \multirow[t]{2}{*}{ Covariable } & \multicolumn{3}{|c|}{ Univariable analysis } & \multicolumn{3}{|c|}{ Multivariable analysis } \\
\hline & HR & $95 \% \mathrm{Cl}$ & $p$ value (CRisk) & $\mathrm{HR}$ & $95 \% \mathrm{Cl}$ & $p$ value (CRRisk) \\
\hline \multicolumn{7}{|l|}{ GSTM1 and GSTT1 genotypes (2 groups) } \\
\hline $\begin{array}{l}\operatorname{GSTM1}(+) / \operatorname{GSTT1}(+) \text { and } \operatorname{GSTM1}(-/-) / \\
\operatorname{GSTT1}(+) \text { and } \operatorname{GSTM1}(+) / \\
\operatorname{GSTT1}(-/-)^{(N=77)}\end{array}$ & Reference & 1 & 0.002 & Reference & 1 & $1.9 \times 10^{-5}$ \\
\hline $\operatorname{GSTM1}(-/-)$ and $\operatorname{GSTT1}(-/-)^{(N=9)}$ & 7.190 & $(2.165-23.874)$ & & 6.521 & $(2.758-15.420)$ & \\
\hline \multicolumn{7}{|l|}{ Diagnosis } \\
\hline ALL & Reference & 1 & 0.232 & Reference & 1 & 0.093 \\
\hline AML & 1.077 & $(0.296-3.925)$ & & & & \\
\hline MDS & 0.384 & $(0.077-1.902)$ & & 0.503 & $(0.225-1.121)$ & \\
\hline \multicolumn{7}{|l|}{ Cum_AUC $(\mathrm{mg} * \mathrm{~h} / \mathrm{L}) \#$} \\
\hline$<59.2$ & Reference & 1 & 0.062 & Reference & 1 & 0.220 \\
\hline $59.2-98.6$ & 3.891 & $(1.327-11.409)$ & & 3.947 & $(0.432-36.040)$ & \\
\hline$>98.6$ & 1.741 & $(0.201-15.055)$ & & & & \\
\hline \multicolumn{7}{|l|}{ AUC_1stDose (mg*h/L) } \\
\hline$<3.7$ & Reference & 1 & 0.090 & Reference & 1 & 0.410 \\
\hline $3.7-6.16$ & 0.729 & $(0.089-5.983)$ & & 0.391 & $(0.041-3.737)$ & \\
\hline$>6.16$ & 2.230 & $(0.276-17.991)$ & & & & \\
\hline \multicolumn{7}{|l|}{ Intensity of conditioning } \\
\hline 2 & Reference & 1 & 0.134 & Reference & 1 & 0.100 \\
\hline 3 or more & 0.382 & $(0.086-1.687)$ & & 0.338 & $(0.091-1.248)$ & \\
\hline \multicolumn{7}{|l|}{ Disease phase } \\
\hline CR1 & Reference & 1 & 0.166 & Reference & 1 & 0.800 \\
\hline CR2 & 1.088 & $(0.230-5.140)$ & & 1.058 & $(0.688-1.626)$ & \\
\hline CR3 or more & 2.042 & $(0.651-6.786)$ & & & & \\
\hline Never treated & 0.329 & $(0.070-1.555)$ & & & & \\
\hline
\end{tabular}

adj adjusted; $A L L$ acute lymphoblastic leukemia; $A M L$ acute myeloid leukemia; $A U C$ dayl area under the curve for BU after the first dose of BU; 95\% CI 95\% confidence interval; CRisk, competing risk analysis of the cumulative incidence of relapse with competing event death; CRRisk multivariate competing risk regression analysis that is presented with Fine-Gray proportional hazard ratios (HR); CR1, first complete remission; CR2, second complete remission; CR3, third complete remission; HR, hazard ratio; disease status; CumAUC, cumulative area under the curve for BU; $M D S$ myelodysplastic syndrome 
Table 2 (continued)

"CR3 or more" included all patients either in CR3 or more or in partial remission or those with $>10 \%$ of circulating myeloblasts before conditioning

*Intensity of conditioning, two alkylating agents (busulfan with cyclophosphamide or melphalan) and three agents (busulfan/cyclophosphamide with melphalan or etoposide)

${ }^{\#}$ CumAUC was calculated after 16 doses administered in $6 \mathrm{~h}$ intervals and is presented in $\mathrm{mg} * \mathrm{~h} / \mathrm{L}$ of which one dose $3.7 \mathrm{mg} * \mathrm{~h} / \mathrm{L}$ is equivalent to $900 \mu \mathrm{M} \times \min$ and $6.16 \mathrm{mg} * \mathrm{~h} / \mathrm{L}$ is equivalent to $1500 \mu \mathrm{M} \times \min$

Bold: significant $p$ values below 0.05

GSTM1-null and GSTT1-null are presented as GSTM1(-/-) and GSTT1(-/-), respectively. GSTM1 non-null and GSTT1 non-null genotypes are presented as $\operatorname{GSTM1}(+)$ and $\operatorname{GSTT1}(+)$, respectively

LCL THP1-CRISPR-Cas9

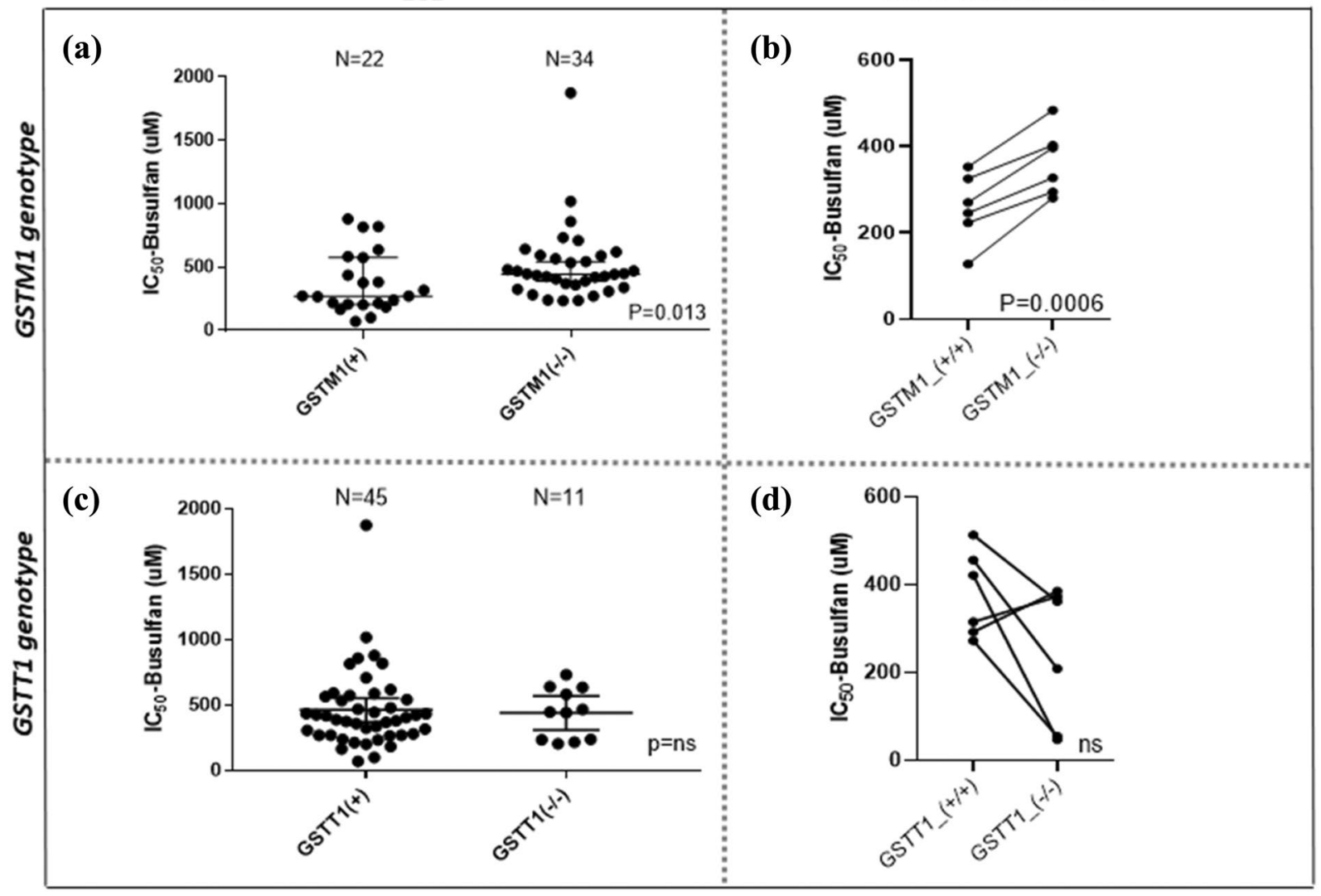

Fig. $2 \mathrm{IC}_{50}$-values for BU in GSTM1-null and GSTT1-null LCLs, THP $1^{\text {GSTM1(-/-) }}$ and THP1 ${ }^{\text {GSTT1(-/-) }}$ cells. IC50 values for BU were stratified according to GSTM1- (A) and GSTT1-null variants (C) in LCLs and CRISPR-Cas9 gene-edited THP1 $1^{\operatorname{GSTM1} 1(-)}(\mathbf{B})$ and THP1 $1^{G S T T 1(-)}$ (D) cell models. Concentration-response titration points were fitted to a Hill equation for BU. The $50 \%$ inhibitory concentrations of $\mathrm{BU}\left(\mathrm{BU}-\mathrm{IC}_{50}\right)$ were determined by dose-response curve fitting using Prism 5.02 software (GraphPad SoftwareInc., CA. USA). The coefficient of determination $\left(R^{2}\right)$ of each plate was used to assess experimental reproducibility and was set to be above 0.95 .

\section{LCL sensitivity to BU is associated with GSTM1, but not with GSTT1 genotypes}

Significantly higher cell viability after treatment with BU was observed in LCLs with GSTM1-null genotype (1.8-fold,
Independent experiments were repeated at least three times. Nonparametric unpaired $t$ test was used in LCLs (A, C). Pairwise comparisons by $t$ test between $G S T(-/-)$ variants in THP1-CRISPR-Cas9 models (B., D.) were used. In THP1-CRISPR-Cas9 cell models (B., D.), dots represented are specific clones with identified $G S T(-/-)$ variants $(+/+$ vs. $-/-)$ based on Sanger DNA-sequencing. $p$ values below 0.05 were considered statistically significant. ns, not significant. GSTM1-null and GSTT1-null are presented as GSTM1(-/-) and GSTT1(-/-), respectively. GSTM1 non-null and GSTT1 non-null genotypes are presented as GSTM1(+) and GSTT1(+), respectively 


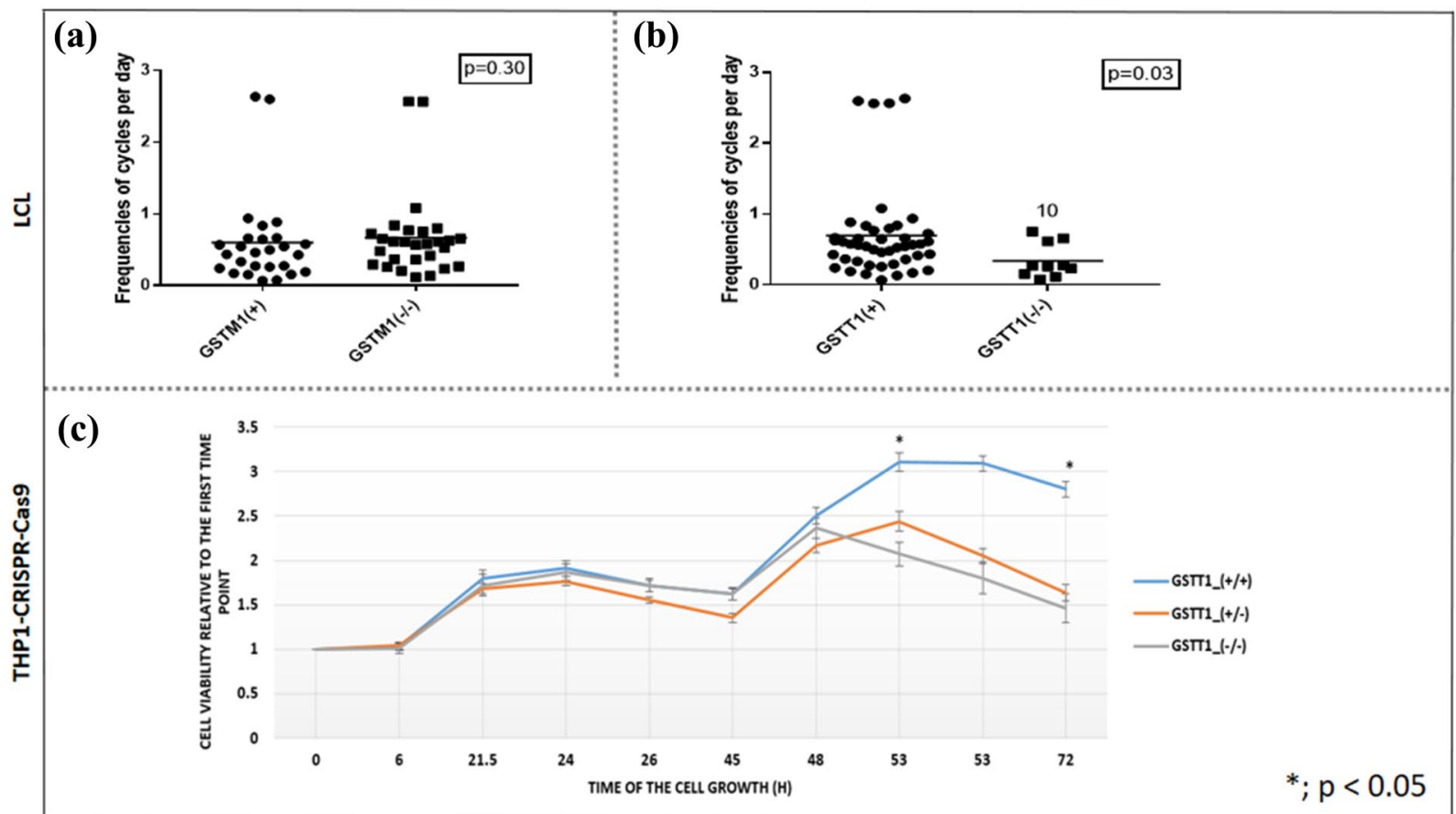

Fig. 3 Baseline cell growth against GSTM1-null and GSTT1-null genotypes in LCLs and THP1 ${ }^{\text {GSTTI(-)-) }}$ cells. Baseline cell growth was assessed against GSTM1-null (A) and GSTT1-null (B) genotypes in LCLs at 48 h end-point analysis and the (C) RealTime Cell Viability assay-Kinetics plot was performed for $72 \mathrm{~h}$ stratified by GSTT1null genotype at baseline (proliferation profile) in THP1 ${ }^{G S T T 1(-/-)}$ cell models. $(\mathbf{A}, \mathbf{B})$ On the $\mathrm{y}$-axis, the basal cell growth rate $(r)$ was calculated using the following formula, appropriate for the usual exponential kinetics of cell growth $(\mathrm{N}$; the number of cells) after the defined time $(t ; h): N_{t}=N_{0} \cdot 2^{\text {tr }}$. (C) Measurement of baseline reduc-

not show a significant association with $\mathrm{BU}-\mathrm{IC}_{50}$ in LCLs and THP $1^{G S T T 1(-/-)}$ cell lines (Fig. 2C, D, respectively). No difference in baseline cell proliferation was seen between GSTM1-null and GSTM1- non-null cells (Fig. 3A), while the proliferation of GSTT1-null cells was significantly decreased in comparison to GSTT1-non-null carriers in LCLs carrying GSTT1-null genotype and THP $1^{\text {GSTT1(-/-) }}[p=0.03$ (LCL, $48 \mathrm{~h}$ end-point measurement, Fig. 3B) and $p<0.05$ (THP1 $^{G S T T 1(-/)}, 72$ h kinetic plot, Fig. 3C)].

\section{GSTM1-null genotype is associated with increased apoptosis and decreased primary necrosis after BU treatment}

In a subgroup of ten GSTM1-null LCLs, we observed increased early apoptosis and a decreased primary necrosis ( $p=0.026$ and 0.006 , respectively) at $48 \mathrm{~h}$ post-treatment with 250,500 and $1000 \mu \mathrm{M}$ of BU in comparison to ten GSTM1-non-null LCLs (Fig. 4A-D). No significant differences between both GSTM1 genotype groups were observed for the number of live cells and apoptotic cells at a later stage ing the potential of viable cells according to GSTT1(-/-) variant in CRISPR-Cas9 gene-edited cell models was performed. The unpaired $t$ test between GST genotypes in LCLs (A., B.) and Pairwise comparisons by $t$ test between GSTT1 genotypes in THP1-CRISPRCas 9 models were used. $p$ values below 0.05 were considered statistically significant. GSTM1-null and GSTT1-null are presented as GSTM1(-/-) and GSTT1(-/-), respectively. GSTM1 non-null and GSTT1 non-null genotypes are presented as GSTM1(+) and GSTT1(+), respectively

(the mix of necrotic and real apoptotic cells). Apoptosis was further assessed through measurement of caspase 3/7 activity according to $G S T(-/-)$ variants showing significantly higher activation in GSTM1-null LCLs and THP1 ${ }^{\text {GSTM1(-/-) }}$ at 250,500 and $1000 \mu \mathrm{M}$ BU in comparison to GSTM1non-null cells ( $p<0.05$; Fig. 4E), while no differences were observed at baseline. BU-induced activation of caspase 3/7 was not significant in GSTT1-null LCLs $(p=0.21)$, while in THP $1^{G S T T 1(-/-)}$ was significantly decreased $(p=0.002$; Fig. 4E) in comparison to GSTT1-non-null cells.

Cell death mechanisms were further followed by kinetic plots. We observed higher apoptotic rates in GSTM1-null cells (THP $1^{G S T M 1(-/-)}$, LCLs) through the whole $72 \mathrm{~h}$ of follow-up after BU treatment when compared to GSTM1non-null cells from unrelated individuals (Supplementary Figs. $4 \mathrm{~A}$ and $4 \mathrm{C}, p<0.0001$ and $p=2.6 \mathrm{E}-05$, respectively). In contrast, we observed lower necrotic rates in GSTM1null cells (THP $1^{G S T M 1(-)-}$, LCLs) that were increasing after $26 \mathrm{~h}$ of BU treatment when compared to GSTM1-non-null cells (Supplementary Figs. 4B, D, $p<0.001$ and 1.4E-05, respectively). Apoptosis at the same time points was lower 

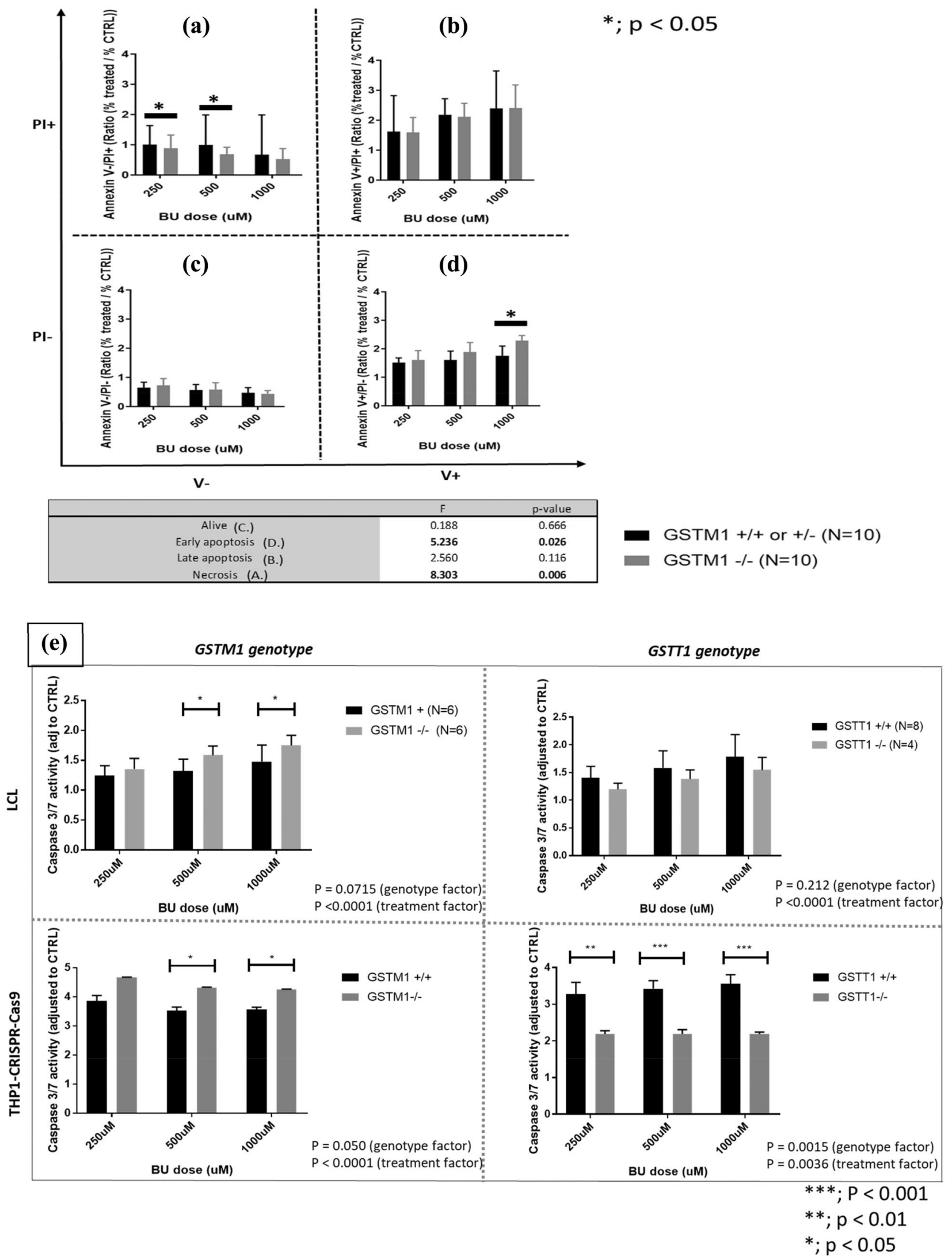
4Fig. 4 Number of necrotic and apoptotic cells in LCLs and caspase $3 / 7$ activity in LCLs, THP $1^{\text {GSTMI(-/-) }}$ and THP $1^{\text {GSTTI(-)- }}$ cells. Flow cytometric analysis (FACS) by using Annexin V/PI assay was used to assess primary necrosis (A), late apoptosis $(\mathbf{B})$, live cells $(\mathbf{C})$ and early apoptosis (D) in LCLs stratified according to GSTM1-null variants; and caspase 3/7 activity (E) in LCLs and THP-CRISPR-Cas9 models stratified according to GST-null variants at 250, 500 and $1000 \mu \mathrm{M}$ BU $48 \mathrm{~h}$ post-treatment. Statistical analysis was performed by two-way ANOVA considering 250, 500 and $1000 \mu \mathrm{M}$ BU concentrations (genotype and treatment factors); $t$ tests between GST(-/-) variants in each condition separately were used; no statistically significant differences were observed between GSTM1 + and GSTM1(-/-) LCLs and THP-CRISPR-Cas9 models in either 1\% DMSO or medium only; $p$ values below 0.05 were considered statistically significant. GSTM1-null and GSTT1-null are presented as GSTM1(-/-) and GSTT1(-/-), respectively. GSTM1 non-null and GSTT1 non-null genotypes are presented as $\operatorname{GSTM1}(+)$ and $\operatorname{GSTT1}(+)$, respectively

in these cells accounting for the faster cell death, mainly as a result of primary necrosis.

\section{[GSSG/GSH ${ }_{\mathrm{T}}$ ] ratios are higher in GSTM1-non-null LCLs and THP1 ${ }^{\text {GSTM1(+++) }}$ cells after BU treatment compared to GSTM1-null while total GSH levels remain unchanged}

At baseline, no differences in $\left[\mathrm{GSSG} / \mathrm{GSH}_{\mathrm{T}}\right]$ ratios were observed between null and non-null LCLs and THP1 cells for the GSTM1 gene. However, $48 \mathrm{~h}$ after $500 \mu \mathrm{M}$ BU treatment, $\left[\mathrm{GSSG} / \mathrm{GSH}_{\mathrm{T}}\right.$ ] ratios were increased 1.6- $(p=0.02$, LCLs) and 1.3-fold ( $p=0.005$, THP1) in GSTM1 non-null compared to GSTM1-null (Fig. 5A, C, respectively). A similar trend was observed after the $250 \mu \mathrm{M} \mathrm{BU}$ treatment ( $48 \mathrm{~h}$ ) in THP $1^{G S T M 1(-/-)}$ in comparison to THP $1^{\text {GSTM1(+/+) }}$ cells (Fig. 5C). In THP1, no significant difference was observed according to GSTT1 genotype after the treatment with BU or at baseline (Fig. 5D). In addition, we observed a significant increase in total GSH levels after the $500 \mu \mathrm{M}$ BU treatment, irrespective of the GSTM1 genotype (Fig. 5B, $p=0.001$ ), thus indicating the potential for BU-related induction of GSH synthesis.

\section{Discussion}

Our clinical association study performed in 86 children with HMs undergoing HSCT following BU-based conditioning regimens demonstrated that patients harboring homozygous deletions in both GSTM1 and GSTT1 genes presented a high risk of relapse $\left(\mathrm{HR}_{\text {relapse }} 7.2\right.$ [95\% Cl, 2.2-23.9; $\left.\left.p=0.002\right]\right)$ and a lower EFS ( $\mathrm{HR}_{\mathrm{EFS}} 4.092$ [95\% Cl, 1.829-9.152; $p=0.001]$ ). After adjustment for known risk factors (diagnosis, disease status, the intensity of conditioning regimen and BU exposure), the association remained significant demonstrating that the deletion of both GST genes is an independent risk factor for relapse (adjusted HR 6.52 [95\%
$\left.\left.\mathrm{CI}, 2.8-15.4 ; p=1.9 \times 10^{-5}\right]\right)$. Although it is a small cohort, this is the first report on the risk of post-HSCT relapse in relation to the germline GSTM1- and GSTT1-null variants in children with HMs. Until now, only one study conducted in BU/CY-based HSCT settings although in adults showed increased relapse rates in patients carrying GSTM1-null genotype, while no association was identified with GSTT1null genotype (Terakura et al. 2020). Concerning non-transplant-based studies in pediatric or adult patients, a similar association between GSTM1/GSTT1 double null carriers and increased risk of relapse (Barragan et al. 2007; Borst et al. 2012; Takanashi et al. 2003, Xiao Q. et al. 2014), lower complete remission rate (Xiao Z. et al. 2008) and lower EFS were demonstrated (Chen et al. 1997; Hall et al. 1994; Leonardi et al. 2017; Rocha et al. 2005; Stanulla et al. 2000; Takanashi et al. 2003; Teachey and Hunger 2013; Woo et al. 2000; Zhang et al. 2017). There are nevertheless a few studies showing no such association (Franca et al. 2012; Zareifar et al. 2013), in which the small number of patients or the different treatment regimens may have mainly precluded defining a relationship between GST variants.

Based on the known detoxifying role of GSTs, our results from the clinical association are contradictory. Although GSTA1 is the main enzyme involved in BU detoxification, GSTM1 is also highly expressed in the liver and recognized as involved in BU conjugation (Ansari et al. 2017; Bremer et al. 2015; Czerwinski et al. 1996; Kim et al. 2011), precluding the BU to cross-link with the DNA strands. Functional variants of the genes coding for GSTs may then interfere in HSCT by affecting BU metabolism. It is known that low BU exposure (CumAUC $<59 \mathrm{mg} \times \mathrm{h} / \mathrm{L}$ ) is associated with graft failure and relapse (Ansari et al. 2017; Bartelink et al. 2016; Philippe et al. 2016), whereas high BU exposure (CumAUC > $98.6 \mathrm{mg} \times \mathrm{h} / \mathrm{L}$ ) could reduce post-HSCT relapse in leukemia at the cost of an increase in organ toxicities, and therefore transplantation-related mortality (Ansari et al. 2017; Bartelink et al. 2016; McCune et al. 2002; McCune and Holmberg 2009; Philippe et al. 2016). However, at the level of HCs, less is known about the direct effect of BU.

We compared BU-related cell death mechanisms in LCLs and THP1 with and without GSTM1 and/or GSTT1 genes after exposure to BU. LCLs were chosen as the in vitro model to resemble heterogeneity seen in a clinical cohort. Since each LCL is derived from a different individual genetic background, the studied effect due to BU is specifically related to the GSTM1- and GSTT1-null and -non-null genotypes. The acute monocytic leukemia (THP1) cell model was selected for the production of the CRISPR-Cas9 GSTM1and/or GSTT1 knockout model, as we have the most patients with a relapsed AML (Supplementary Table 3). Selection of these two cell models aids in evaluating BU-dependent and -independent GSTT1 and GSTM1 effects. We demonstrated 


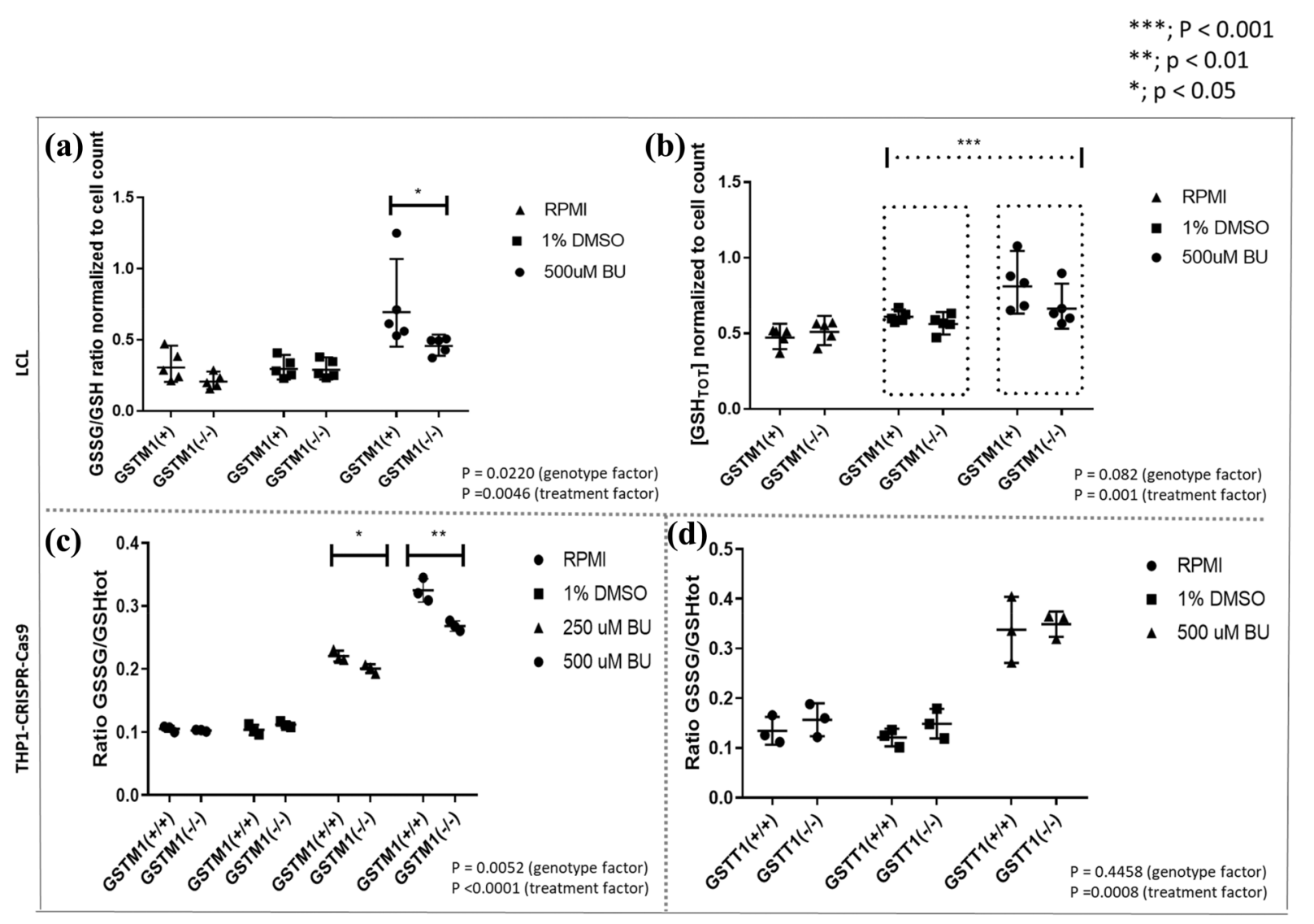

Fig. 5 Glutathione levels in LCLs stratified according to GSTM1null variant, THP1 ${ }^{\text {GSTM1(-/-) }}$ and THP1 $1^{\text {GSTTI(-/-) }}$ cells. [GSSG/GSH ${ }_{\mathrm{T}}$ ] ratio (A) and $\mathrm{GSH}_{\mathrm{T}}(\mathbf{B})$ in LCLs were calculated stratified according to GSTM1-null variant; and [GSSG/GSH ${ }_{\mathrm{T}}$ ] ratios in CRISPR-Cas9 edited THP1 $1^{\text {GSTM1(-/-) }}(\mathbf{C})$ and THP1 $1^{\text {GSTTI(-/-) }}$ (D) cell models after the treatment with $500 \mu \mathrm{M}$ BU. Statistical analysis was performed by the two-way ANOVA considering 250 or $500 \mu \mathrm{M}$ BU concentration (genotype factor); $t$ tests between $G S T(-/-$ ) variants in each condi-

that only GSTM1-null (but not GSTT1-null) is associated with higher resistance to $\mathrm{BU}$ as determined by higher

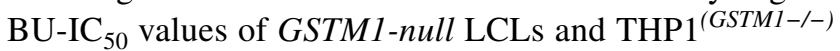
in comparison to GSTM1-non-null cells. This could be due to a change in the redox equilibrium as demonstrated by lower levels of oxidized GSH, lower primary necrosis and higher early apoptosis. An increase of GSTM1-null LCL's viability was confirmed either by continuous follow-up of redox potential within $72 \mathrm{~h}$. Apoptosis/necrosis kinetic results demonstrate that $\mathrm{BU}$-induced apoptotic processes are more pronounced in GSTM1-null LCLs. In contrast, primary necrotic cell death was more pronounced in GSTM1non-null cells when comparing with the GSTM1-null cells. In addition, primary necrosis was significantly induced at an earlier stage in GSTM1-non-null cells. These results show that GSTM1-null variants can modulate BU-induced cell death, which were supplemented further by increased activation of known apoptotic markers caspase- 3 or -7 in tion separately were used; no statistically significant differences were observed between $G S T(-/-)$ variants in LCLs and THP-CRISPRCas9 models in either 1\% DMSO or medium; $p$ values below 0.05 were considered statistically significant. GSTM1-null and GSTT1-null are presented as GSTM1(-/-) and GSTT1(-/-), respectively. GSTM1 non-null and GSTT1 non-null genotypes are presented as GSTM1(+) and $\operatorname{GSTT1}(+)$, respectively

GSTM1-null LCLs and THP1 in comparison to GSTM1-nonnull cells. Importantly, observed reduced rates of GSTM1dependent cell death cannot be attributed to the increased baseline cell proliferation.

The findings of higher primary necrosis, lower early apoptosis and lower cell viability in GSTM1-non-null HCs compared to GSTM1-null cells treated with BU were unexpected. Contrary to our observations, many studies showed associations between increased expression or activity of GSTs and resistance mechanisms against a range of cytotoxic drugs (Hoban et al. 1992; Smith et al. 1989). These results could potentially be explained by not only direct detoxification with GSH, but also through negative regulation of pro-apoptotic protein kinases, such as apoptosis signal-regulating kinase 1 (ASK1) (Board and Menon 2013; Tew and Townsend 2012). For instance, stress conditions cause the release of ASK1 from GSTM1, thereby leading to induction of apoptosis, which was shown in our experiments 
after induction with BU. In addition, GSTM1-null cells carrying more free ASK1 for phosphorylation activation are expected to have more apoptosis upon BU-induced stress in comparison to GSTM1-null cells which is in accordance with our in vitro results.

However, the observed paradox in increased cell death of GSTM1 well-expressed cells upon BU treatment could additionally be explained by findings of the study of DeLeve et al. (2000), demonstrating that in murine hepatocytes BU is cytotoxic also through oxidative stress caused by $\mathrm{BU}$ metabolites (BU glutathione S-conjugate thiophenium ion, $\mathrm{GS}^{+} \mathrm{THT}$ ) and by the depletion of GSH in addition to DNA alkylation. The toxic metabolites of BU/GSH metabolism are mainly oxidized by flavin-containing monooxygenases (FMOs, e.g., FMO3) and cytochromes (CYPs, e.g., CYP3A4) (El-Serafi et al. 2017) to water-soluble non-toxic metabolites [e.g., sulfolane (Uppugunduri et al. 2017)]. However, CYP3A4 and FMO3 are mainly expressed in the liver (accounting for 54\% of overall tetrahydrothiophene [THT] disappearance, the metabolite of BU), and less in LCLs, as observed in our laboratory (data not shown) and by others (https://www.proteinatlas.org). After RNA sequencing in LCLs, very low or no gene expressions of $C Y P 2 D 6$, 2C19, 2C9, 2B6, 2C8, 4A11, 3A4, FMOI and FMO3 were identified. In this context, the oxidative burst caused by electrophilic molecules from BU-GSH conjugation (Udensi and Tchounwou 2014; Zmorzynski et al. 2015) in addition to the absence of CYP3A4 and FMO3 could be a reason for the lower sensitivity of GSTM1-null HCs to BU, as observed in LCLs and THP1. In contrast, higher total expressions of CYPs and FMOs in hepatocytes (El-Serafi et al. 2017) could explain why GSTA1-slow BU metabolizing individuals in addition to the absence of GSTM1 activity show potentially more treatment-related toxicities [e.g., SOS (Srivastava et al. 2004) and aGvHD (Elhasid et al. 2010)] than carriers with normal GST's enzyme activities. A hypothetical comparative model of the difference in BU fate between hepatocytes and lymphocytes is suggested in Supplementary Fig. 5 and warrants further investigation.

The genetically determined different cell fate after BU exposure might explain the apparently discordant results between the relapse incidence in patients carrying GSTM1null genotype (in combination with GSTT1-null) and the cellular resistance to BU in GSTM1-null LCLs and

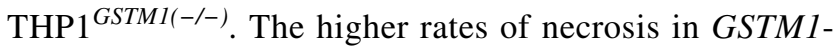
non-null cells might predict a pro-inflammatory cell death of the malignant cells, resulting in enhanced immunogenicity (Sachet et al. 2017). Unlike the other chemotherapeutic regimens including autologous transplantation, the efficacy of the allogeneic transplantation relies on the graft-versusleukemia effect, especially in HMs (Horowitz et al. 1990; Yeshurun et al. 2019), but that theory should be further explored.
Another relevant observation is the significantly increased post-HSCT relapse in GSTT1-null when combined with GSTM1-null genotype in children with HMs. The link between GSTT1 and post-HSCT relapse is not clear yet. Our in vitro observations cannot be attributed to the BU-related differences in $\mathrm{IC}_{50}$ values or $\left[\mathrm{GSSG} / \mathrm{GSH}_{\mathrm{T}}\right]$ ratios. Other pharmacogenomics studies also demonstrated that genetic variations in GSTT1 are not associated with BU clearance or liver toxicity (Gaziev et al. 2010; Goekkurt et al. 2007; Kim et al. 2011; Srivastava et al. 2004). Nevertheless, we observed faster baseline proliferation in GSTT1-non-null LCLs/THP1 and a slightly higher baseline increase of caspase 3/7 activation compared to those with GSTT1-null genotype, indicating GSTT1 potential involvement of BUindependent mechanisms in the relapse development.

The results of the present clinical study are limited by the retrospective study design and relatively small pediatric sample size with no clinical validation cohort. However, the sample size of 86 patients has at least $80 \%$ power with $10 \%$ of observed combined GSTM1/GSTT1 double null variants' frequency and relapse incidence with the estimated observed effect size of $\geq 7.0$ and alpha value of 0.05 . The primary diagnosis of HMs was made at the referring institution and was not centrally reviewed. Well-known risk factors such as somatic genetic/cytogenetics abnormalities, the donor DNA and the initial response to the treatment (e.g., MRD) were not available. However, as described in Supplementary Table 2, similar characteristics were present between the $G S T$ genetic subgroups ( $p$ values $>0.05$ ). The GST-null variants were not associated with the status of the disease before HSCT and we assume that the germline genotype impact on protein expression was present in malignant cells as shown by Weiss et al. (2007). The majority of cases in our study underwent a BU-CY conditioning regimen; however, it is not known if this association is specific to a BU-CY conditioning regimen only or unspecific to other chemotherapeutics used in the HSCT setting (e.g., Thio or Mel) (Hao et al. 2020). For instance, active metabolites of CY (e.g., acrolein) are also eliminated by GSH conjugation catalyzed by GSTs (Uppugunduri et al. 2017). This needs to be evaluated in the future with a focus on whether GSTs play a major role in determining clinical outcomes. This aspect is currently being evaluated by our group using a cohort from multiple centers with the usage of multiple conditioning regimens. Furthermore, the transplant-related mortality or combined toxicities were not associated with the GSTM1- and GSTT1null variants (data are not shown), suggesting compensation of BU conjugation by other GSTs, especially GSTA1, which is mainly expressed in hepatocytes and other somatic cells. 


\section{Conclusions}

In summary, we report that GSTM1/GSTT1 double null genotypes could serve as genetic biomarkers for identifying pediatric patients with HMs at higher risk of relapse after an allogeneic HSCT following BU-containing conditioning. On the other hand, the absence of those markers might predict the patients who more likely will respond to the chemotherapy-based conditioning. Functional studies indicated different mechanisms of cell death upon exposure to BU based on the presence or absence of GST-null alleles and the in vivo impact of those findings must be further explored.

Supplementary Information The online version contains supplementary material available at https://doi.org/10.1007/s00432-021-03769-2.

Acknowledgements We warmly thank the patients and their parents for consenting to participate in this study. We also thank Laurence Lesne, Mary Khoshbeen, Denis Marino, Rodolfo Lo Piccolo, Benedict Dupraz, Anuj Kumar Tyagi and Eva Choong for the help in this study as well as the Swiss Pediatric Oncology Group.

Authors' contributions SJM, CRSU, MA designed the study; SJM, VM, CRSU executed cell viability experiments; SJM, CRSU isolated DNA/mRNA and genotyping from cell lines; SJM, VM contributed to apoptosis and necrosis-based experiments and produced CRISPRCas9 THP1 knockout cell models; SJM executed real-time viability and apoptosis/necrosis, caspase 3/7 and GSH -based experiments and western blotting; SJM, CRSU, SR: GST activity; MA, MAR, YC, JJB, RGMB, JHD, CP, SC, HB, MK contributed to patients' sample and clinical data processing; SJM executed computational and statistical analysis of clinical data that were verified by MA, TN, CRSU, HB; SJM, MA, VM, TN, CRSU contributed to interpretation of results; SJM drafted the manuscript; all authors revised the study critically. MA had final responsibility for the decision to submit for publication. All the authors read and approved the final manuscript.

Funding Open Access funding provided by Université de Genève. This study was performed thanks to the contribution of the Swiss National Science Foundation (ME9870/320030-153389, PI: Marc Ansari), the OAK foundation (OCAY-17-642, PI: Marc Ansari) and the CANSEARCH foundation (PI: Marc Ansari).

Data availability All data presented are provided freely in this manuscript including any supplementary data. The raw datasets used and/or analyzed during the current study are available from the corresponding author on reasonable request.

Code availability Not applicable.

\section{Declarations}

Conflict of interest The authors declare that they have no competing interests related to the submitted work.

Ethics approval The Institutional Review Board or ethics committees approved the study.

consent to participate All patients and/or parents provided informed consent.
Consent for publication All authors are aware of the study and approve of this submission.

Open Access This article is licensed under a Creative Commons Attribution 4.0 International License, which permits use, sharing, adaptation, distribution and reproduction in any medium or format, as long as you give appropriate credit to the original author(s) and the source, provide a link to the Creative Commons licence, and indicate if changes were made. The images or other third party material in this article are included in the article's Creative Commons licence, unless indicated otherwise in a credit line to the material. If material is not included in the article's Creative Commons licence and your intended use is not permitted by statutory regulation or exceeds the permitted use, you will need to obtain permission directly from the copyright holder. To view a copy of this licence, visit http://creativecommons.org/licenses/by/4.0/.

\section{References}

Ansari M et al (2017) GSTA1 diplotypes affect busulfan clearance and toxicity in children undergoing allogeneic hematopoietic stem cell transplantation: a multicenter study. Oncotarget 8:90852-90867

Balta G, Yuksek N, Ozyurek E, Ertem U, Hicsonmez G, Altay C, Gurgey A (2003) Characterization of MTHFR, GSTM1, GSTT1, GSTP1, and CYP1A1 genotypes in childhood acute leukemia. Am J Hematol 73:154-160

Barragan E, Collado M, Cervera J, Martin G, Bolufer P, Roman J, Sanz MA (2007) The GST deletions and NQO1*2 polymorphism confers interindividual variability of response to treatment in patients with acute myeloid leukemia. Leuk Res 31:947-953

Barrett AJ, Battiwalla M (2010) Relapse after allogeneic stem cell transplantation. Expert Rev Hematol 3:429-441

Bartelink IH et al (2016) Association of busulfan exposure with survival and toxicity after haemopoietic cell transplantation in children and young adults: a multicentre, retrospective cohort analysis. Lancet Haematol 3:e526-e536

Board PG, Menon D (2013) Glutathione transferases, regulators of cellular metabolism and physiology. Biochim Biophys Acta 1830:3267-3288

Borst L, Buchard A, Rosthoj S, Wesolowska A, Wehner PS, Wesenberg F, Dalhoff K, Schmiegelow K (2012) Gene dose effects of GSTM1, GSTT1 and GSTP1 polymorphisms on outcome in childhood acute lymphoblastic leukemia. J Pediatr Hematol Oncol 34:38-42

Bremer S, Floisand Y, Brinch L, Gedde-Dahl T, Bergan S (2015) Glutathione transferase gene variants influence busulfan pharmacokinetics and outcome after myeloablative conditioning. Ther Drug Monit 37:493-500

Chen CL, Liu Q, Pui CH, Rivera GK, Sandlund JT, Ribeiro R, Evans WE, Relling MV (1997) Higher frequency of glutathione S-transferase deletions in black children with acute lymphoblastic leukemia. Blood 89:1701-1707

Ciurea SO, Andersson BS (2009) Busulfan in hematopoietic stem cell transplantation. Biol Blood Marrow Transplant 15:523-536

Czerwinski M, Gibbs JP, Slattery JT (1996) Busulfan conjugation by glutathione S-transferases alpha, mu, and pi. Drug Metab Dispos 24:1015-1019

Czerwinski M, Kiem HP, Slattery JT (1997) Human CD34+ cells do not express glutathione S-transferases alpha. Gene Ther 4:268-270

DeLeve LD, Wang X (2000) Role of oxidative stress and glutathione in busulfan toxicity in cultured murine hepatocytes. Pharmacology $60: 143-154$ 
Elhasid R, Krivoy N, Rowe JM, Sprecher E, Adler L, Elkin H, Efrati E (2010) Influence of glutathione S-transferase A1, P1, M1, T1 polymorphisms on oral busulfan pharmacokinetics in children with congenital hemoglobinopathies undergoing hematopoietic stem cell transplantation. Pediatr Blood Cancer 55:1172-1179

El-Serafi I, Terelius Y, Abedi-Valugerdi M, Naughton S, Saghafian M, Moshfegh A, Mattsson J, Potacova Z, Hassan M (2017) Flavincontaining monooxygenase 3 (FMO3) role in busulphan metabolic pathway. PLoS ONE 12:e187294

Fine JP, Gray RJ (1999) A proportional hazards model for the subdistribution of a competing risk. J Am Stat Assoc 94:496-509

Franca R et al (2012) Glutathione S-transferase homozygous deletions and relapse in childhood acute lymphoblastic leukemia: a novel study design in a large Italian AIEOP cohort. Pharmacogenomics 13:1905-1916

Gaziev J et al (2010) Novel pharmacokinetic behavior of intravenous busulfan in children with thalassemia undergoing hematopoietic stem cell transplantation: a prospective evaluation of pharmacokinetic and pharmacodynamic profile with therapeutic drug monitoring. Blood 115:4597-4604

Goekkurt E, Stoehlmacher J, Stueber C, Wolschke C, Eiermann T, Iacobelli S, Zander AR, Ehninger G, Kroger N (2007) Pharmacogenetic analysis of liver toxicity after busulfan/cyclophosphamide-based allogeneic hematopoietic stem cell transplantation. Anticancer Res 27:4377-4380

Gray RJ (1988) A class of K-sample tests for comparing the cumulative incidence of a competing risk. Ann Stat 16:1141-1154

Hall AG, Autzen P, Cattan AR, Malcolm AJ, Cole M, Kernahan J, Reid MM (1994) Expression of mu class glutathione S-transferase correlates with event-free survival in childhood acute lymphoblastic leukemia. Cancer Res 54:5251-5254

Hamilton BK, Copelan EA (2012) Concise review: the role of hematopoietic stem cell transplantation in the treatment of acute myeloid leukemia. Stem Cells 30:1581-1586

Hao C, Ma X, Wang L, Zhang W, Hu J, Huang J, Yang W (2020) Predicting the presence and mechanism of busulfan drug-drug interactions in hematopoietic stem cell transplantation using pharmacokinetic interaction network-based molecular structure similarity and network pharmacology. Eur J Clin Pharmacol 77(4):595-605

Hoban PR, Robson CN, Davies SM, Hall AG, Cattan AR, Hickson ID, Harris AL (1992) Reduced topoisomerase II and elevated alpha class glutathione $\mathrm{S}$-transferase expression in a multidrug resistant $\mathrm{CHO}$ cell line highly cross-resistant to mitomycin C. Biochem Pharmacol 43:685-693

Horowitz MM et al (1990) Graft-versus-leukemia reactions after bone marrow transplantation. Blood 75:555-562

Kim SD et al (2011) Influence of GST gene polymorphisms on the clearance of intravenous busulfan in adult patients undergoing hematopoietic cell transplantation. Biol Blood Marrow Transplant $17: 1222-1230$

Lee CJ et al (2020) Late effects after ablative allogeneic stem cell transplantation for adolescent and young adult acute myeloid leukemia. Blood Adv 4:983-992

Leonardi DB, Abbate M, Riccheri MC, Nunez M, Alfonso G, Gueron G, De Siervi A, Vazquez E, Cotignola J (2017) Improving risk stratification of patients with childhood acute lymphoblastic leukemia: Glutathione-S-Transferases polymorphisms are associated with increased risk of relapse. Oncotarget 8:110-117

Li M, Zheng M, Chen H, Yu H (2018) Effects of GST variants on the risk odds of hematological malignancy: a meta-analysis. J Cell Biochem 120(5):8570-8580

Lin DX, Tang YM, Peng Q, Lu SX, Ambrosone CB, Kadlubar FF (1998) Susceptibility to esophageal cancer and genetic polymorphisms in glutathione S-transferases T1, P1, and M1 and cytochrome P450 2E1. Cancer Epidemiol Biomarkers Prev 7:1013-1018

Marin F, Garcia N, Munoz X, Capella G, Gonzalez CA, Agudo A, Sala N (2010) Simultaneous genotyping of GSTT1 and GSTM1 null polymorphisms by melting curve analysis in presence of SYBR Green I. J Mol Diagn 12:300-304

McCune JS, Holmberg LA (2009) Busulfan in hematopoietic stem cell transplant setting. Expert Opin Drug Metab Toxicol 5:957-969

McCune JS, Gooley T, Gibbs JP, Sanders JE, Petersdorf EW, Appelbaum FR, Anasetti C, Risler L, Sultan D, Slattery JT (2002) Busulfan concentration and graft rejection in pediatric patients undergoing hematopoietic stem cell transplantation. Bone Marrow Transplant 30:167-173

Myers AL, Kawedia JD, Champlin RE, Kramer MA, Nieto Y, Ghose R, Andersson BS (2017) Clarifying busulfan metabolism and drug interactions to support new therapeutic drug monitoring strategies: a comprehensive review. Expert Opin Drug Metab Toxicol 13:901-923

Peters C et al (2021) Total body irradiation or chemotherapy conditioning in childhood all: a multinational, randomized, noninferiority phase III study. J Clin Oncol 39:295-307

Philippe M, Goutelle S, Guitton J, Fonrose X, Bergeron C, Girard P, Bertrand Y, Bleyzac N (2016) Should busulfan therapeutic range be narrowed in pediatrics? Experience from a large cohort of hematopoietic stem cell transplant children. Bone Marrow Transplant 51:72-78

Rocha JC et al (2005) Pharmacogenetics of outcome in children with acute lymphoblastic leukemia. Blood 105:4752-4758

Sachet M, Liang YY, Oehler R (2017) The immune response to secondary necrotic cells. Apoptosis 22:1189-1204

Saitou M, Ishida T (2015) Distributions of the GSTM1 and GSTT1 null genotypes worldwide are characterized by latitudinal clines. Asian Pac J Cancer Prev 16:355-361

Shah NN, Borowitz MJ, Steinberg SM, Robey NC, Gamper CJ, Symons HJ, Loeb DM, Wayne AS, Chen AR (2014) Factors predictive of relapse of acute leukemia in children after allogeneic hematopoietic cell transplantation. Biol Blood Marrow Transplant 20:1033-1039

Smith MT, Evans CG, Doane-Setzer P, Castro VM, Tahir MK, Mannervik B (1989) Denitrosation of 1,3-bis(2-chloroethyl)-1-nitrosourea by class mu glutathione transferases and its role in cellular resistance in rat brain tumor cells. Cancer Res 49:2621-2625

Srivastava A, Poonkuzhali B, Shaji RV, George B, Mathews V, Chandy M, Krishnamoorthy R (2004) Glutathione S-transferase M1 polymorphism: a risk factor for hepatic venoocclusive disease in bone marrow transplantation. Blood 104:1574-1577

Stanulla M, Schrappe M, Brechlin AM, Zimmermann M, Welte K (2000) Polymorphisms within glutathione S-transferase genes (GSTM1, GSTT1, GSTP1) and risk of relapse in childhood B-cell precursor acute lymphoblastic leukemia: a case-control study. Blood 95:1222-1228

Takanashi M, Morimoto A, Yagi T, Kuriyama K, Kano G, Imamura T, Hibi S, Todo S, Imashuku S (2003) Impact of glutathione S-transferase gene deletion on early relapse in childhood B-precursor acute lymphoblastic leukemia. Haematologica 88:1238-1244

Teachey DT, Hunger SP (2013) Predicting relapse risk in childhood acute lymphoblastic leukaemia. Br J Haematol 162:606-620

Terakura S et al (2020) Analysis of glutathione S-transferase and cytochrome $\mathrm{P} 450$ gene polymorphism in recipients of doseadjusted busulfan-cyclophosphamide conditioning. Int J Hematol 111:84-92

Tew KD, Townsend DM (2012) Glutathione-s-transferases as determinants of cell survival and death. Antioxid Redox Signal $17: 1728-1737$ 
Udensi UK, Tchounwou PB (2014) Dual effect of oxidative stress on leukemia cancer induction and treatment. J Exp Clin Cancer Res 33:106

Uppugunduri CRS et al (2017) The association of combined GSTM1 and CYP2C9 genotype status with the occurrence of hemorrhagic cystitis in pediatric patients receiving myeloablative conditioning regimen prior to allogeneic hematopoietic stem cell transplantation. Front Pharmacol 8:451

Weiss JR, Baer MR, Ambrosone CB, Blanco JG, Hutson A, Ford LA, Moysich KB (2007) Concordance of pharmacogenetic polymorphisms in tumor and germ line DNA in adult patients with acute myeloid leukemia. Cancer Epidemiol Biomarkers Prev 16:1038-1041

Woo MH et al (2000) Glutathione S-transferase genotypes in children who develop treatment-related acute myeloid malignancies. Leukemia 14:232-237

Xiao Z, Yang L, Xu Z, Zhang Y, Liu L, Nie L, Li L, Wang J, Hao Y (2008) Glutathione S-transferases (GSTT1 and GSTM1) genes polymorphisms and the treatment response and prognosis in Chinese patients with de novo acute myeloid leukemia. Leuk Res 32:1288-1291

Xiao Q, Deng D, Li H, Ye F, Huang L, Zhang B, Ye B, Mo Z, Yang X, Liu Z (2014) GSTT1 and GSTM1 polymorphisms predict treatment outcome for acute myeloid leukemia: a systematic review and meta-analysis. Ann Hematol 93:1381-1390

Yeshurun M et al (2019) The impact of the graft-versus-leukemia effect on survival in acute lymphoblastic leukemia. Blood Adv 3:670-680

Zareifar S, Monabati A, Saeed A, Fakhraee F, Cohan N (2013) The association of glutathione S-transferase gene mutations (including GSTT1 and GSTM1) with the prognostic factors and relapse in acute lymphoblastic leukemia. Pediatr Hematol Oncol 30:568-573

Zhang HY, Zhang J, Wu T, Bai H (2017) Polymorphism of glutathione S-transferases and genetic sensitivity of childhood acute lymphoblastic leukemia: a meta-analysis. Zhongguo Shi Yan Xue Ye Xue Za Zhi 25:16-23

Zmorzynski S, Swiderska-Kolacz G, Koczkodaj D, Filip AA (2015) Significance of polymorphisms and expression of enzyme-encoding genes related to glutathione in hematopoietic cancers and solid tumors. Biomed Res Int 2015:853573

Publisher's Note Springer Nature remains neutral with regard to jurisdictional claims in published maps and institutional affiliations.

\section{Authors and Affiliations}

\section{Simona Jurkovic Mlakar ${ }^{1,2}$ - Satyanarayana Chakradhara Rao Uppugunduri ${ }^{1,2} \cdot$ Tiago Nava $^{1,2} \cdot$ Vid Mlakar $^{1,2}$. Hadrien Golay ${ }^{1,2}$. Shannon Robin ${ }^{1,2} \cdot$ Nicolas Waespe $^{1,3} \cdot$ Mohamed Aziz Rezgui $^{4} \cdot$ Yves Chalandon $^{5}$. Jaap Jan Boelens ${ }^{6} \cdot$ Robert G. M. Bredius $^{7}$. Jean-Hugues Dalle ${ }^{8} \cdot$ Christina Peters $^{9} \cdot$ Selim Corbacioglu ${ }^{10}$. Henrique Bittencourt ${ }^{4,11,12,13}$. Maja Krajinovic ${ }^{4,11,12,13}$. Marc Ansari ${ }^{1,2}$ on behalf of the paediatric diseases working party of the European society for blood and marrow transplantation}

1 CANSEARCH Research Platform in Paediatric Oncology and Haematology, Department of Paediatrics, Gynecology and Obstetrics, Faculty of Medicine, University of Geneva, Geneva, Switzerland

2 Division of Paediatric Oncology and Haematology, Department of Women, Children and Adolescents, Pediatric Oncology and Hematology Unit, Geneva University Hospitals and University of Geneva, Rue Willy-Donzé 6; Bureau 5-507, 1211 Genève, Switzerland

3 Institute of Social and Preventive Medicine, University of Bern, Bern, Switzerland

4 Charles-Bruneau Cancer Center, CHU Sainte-Justine Research Center, Montreal, QC, Canada

5 Division of Haematology, Department of Oncology, Geneva University Hospital and Faculty of Medicine, University of Geneva, Geneva, Switzerland

6 Paediatric Blood and Marrow Transplantation Program, University Medical Center Utrecht, Utrecht, The Netherlands
7 Department of Pediatrics, Leiden University Medical Center, Leiden, The Netherlands

8 Paediatric Haematology Department, Robert Debré Hospital, Assistance Publique, Hôpitaux de Paris, Paris, France

9 St Anna Children's Hospital, Department of Pediatrics, Medical University Vienna, Vienna, Austria

10 Department of Pediatric Hematology, Oncology and Stem Cell Transplantation, University of Regensburg, Regensburg, Germany

11 Department of Paediatrics, Faculty of Medicine, University of Montreal, Montreal, QC, Canada

12 Present Address: Clinical Pharmacology Unit, CHU Sainte-Justine, Montreal, QC, Canada

13 Department of Pharmacology, Faculty of Medicine, University of Montreal, Montreal, QC, Canada 